\title{
Incorporating ex-vivo lung perfusion into the UK adult lung transplant service: an economic evaluation and decision analytic model
}

\author{
N. McMeekin ${ }^{1 *}$ (D, A. E. Chrysos ${ }^{2,3}$ (D) L. Vale ${ }^{2}$ (i) and A. J. Fisher ${ }^{4,5}$ (B)
}

\begin{abstract}
Background: An estimated 20-30\% of end-stage lung disease patients awaiting lung transplant die whilst on the waiting list due to a shortage of suitable donor lungs. Ex-Vivo Lung Perfusion is a technique that reconditions donor lungs initially not deemed usable in order to make them suitable for transplantation, thereby increasing the donor pool. In this study, an economic evaluation was conducted as part of DEVELOP-UK, a multi-centre study assessing the clinical and cost-effectiveness of the Ex-Vivo Lung Perfusion technique in the United Kingdom.

Methods: We estimated the cost-effectiveness of a UK adult lung transplant service combining both standard and ExVivo Lung Perfusion transplants compared to a service including only standard lung transplants. A Markov model was developed and populated with a combination of DEVELOP-UK, published and clinical routine data, and extrapolated to a lifetime horizon. Probabilistic sensitivity and scenario analyses were used to explore uncertainty in the final outcomes.

Results: Base-case model results estimated life years gained of 0.040, quality-adjusted life-years (QALYS) gained of 0.045 and an incremental cost per QALY of $£ 90,000$ for Ex-Vivo Lung Perfusion. Scenario analyses carried out suggest that an improved rate of converting unusable donor lungs using Ex-Vivo Lung Perfusion, similar resource use post-transplant for both standard and EVLP lung transplant and applying increased waiting list costs would reduce ICERs to approximately $£ 30,000$ or below.

Conclusion: DEVELOP-UK base-case results suggest that incorporating EX-Vivo Lung Perfusion into the UK adult lung transplant service is more effective, increasing the number of donor lungs available for transplant, but would not currently be considered cost-effective in the UK using the present NICE threshold. However, results were sensitive to change in some model parameters and in several plausible scenario analyses results indicate that a service incorporating Ex-vivo lung perfusion would be considered cost-effective .
\end{abstract}

Trial registration: ISRCTN registry number: ISRCTN44922411.

Date of registration: 06/02/2012.

Retrospectively registered.

Keywords: Ex-vivo lung perfusion, EVLP, Lung transplantation, Lung transplant waiting list, Cost-effectiveness, Cost utility analysis, Markov model, Decision analytic model, Economic evaluation

\footnotetext{
* Correspondence: nicola.mcmeekin@glasgow.ac.uk

'HEHTA, Institute of Health and Wellbeing, University of Glasgow, Glasgow,

UK

Full list of author information is available at the end of the article
}

(c) The Author(s). 2019 Open Access This article is distributed under the terms of the Creative Commons Attribution 4.0 International License (http://creativecommons.org/licenses/by/4.0/), which permits unrestricted use, distribution, and reproduction in any medium, provided you give appropriate credit to the original author(s) and the source, provide a link to the Creative Commons license, and indicate if changes were made. The Creative Commons Public Domain Dedication waiver (http://creativecommons.org/publicdomain/zero/1.0/) applies to the data made available in this article, unless otherwise stated. 


\section{Background}

Respiratory disease accounts for one in five deaths in the UK [1]. Lung transplantation provides the only life prolonging treatment option for a select few patients with end-stage lung disease. Whilst not all those with end stage lung disease might be suitable for lung transplantation, a shortage of suitable donor lungs results in around $20-30 \%$ of patients dying whilst on the lung transplant (LTx) waiting list [2]. Although the number of potential donors is limited, the primary cause of this shortage is that approximately $80 \%$ of potential donor lungs are felt to be unusable for standard LTx due to irreversible pre-existing lung disease or by reversible damage occurring during end-of-life care [3].

One solution to this problem is Ex-Vivo Lung Perfusion (EVLP), a novel technique used to increase the existing donor pool by assessing and reconditioning donor lungs felt to be unusable in order to make them clinically safe for LTx [4]. These donor lungs are attached to the EVLP apparatus, ventilated, warmed to body temperature and flushed with perfusate, donor lungs are then assessed for suitability for transplant. The first successful EVLP LTx took place in 2005 [5] and by 2014, around 350 EVLP transplants had taken place worldwide [6]. Initial experience has shown that EVLP can increase the number of LTxs by 15 to 30\% [6]. However, a definitive study would be needed to establish the safety, effectiveness and cost-effectiveness of this technique compared with standard transplant.

\section{Summary of DEVELOP-UK}

DEVELOP-UK was a multi-centre, unblinded, non-randomized, non-inferiority observational study that sought to evaluate the clinical- and cost-effectiveness of the EVLP technique compared with standard lung transplantation in the UK [4]. Participants were adults $(\geq 18$ years) who had already been accepted onto the UK LTx waiting list. The target sample size was 306 in the standard transplant arm and 102 in the EVLP arm. Non-inferiority was assumed if the hazard rate of death during the first year was not more than doubled by the use of EVLP.

Four hundred and eighty-seven participants were recruited into the study, 202 received a LTx; 184 standard and 18 EVLP. The small numbers in the EVLP arm led to the study being terminated before the recruitment targets were reached. Baseline characteristics of transplant recipients in each arm are presented in Table 1. Results of the study showed that a third of the donor lungs subjected to EVLP were deemed suitable for transplant (18 out of 53) representing a $10 \%$ increase in existing standard LTx activity due to EVLP transplants. One-year survival in the EVLP arm was lower than in the standard arm, $67 \%$ compared to $80 \%$. However, the non-inferiority definition of the study was satisfied. The small numbers of individuals receiving transplants means that the study was underpowered and non-inferiority was not established. An unexpected consequence during the study was an increase in standard LTxs; one centre witnessed an increase of $25 \%$. Overall in the UK, the increase in the number of LTxs was $6.9 \%$ in the first year of the trial (2012/13), and the increase from pre-trial was $20 \%$ in the second year (2013/14). In the year after the trial finished (2014/15), the number of transplants returned to almost pre-trial rates; an increase of only $1.7 \%$ compared to the levels pre-trial [7]. The proposed economic evaluation was a simple head-to-head comparison of EVLP compared to standard lung transplantation, not accounting for any spill-over effects. The cost of an EVLP transplant was approximately $£ 35,000$ higher than a standard LTx, and quality-adjusted life-years (QALYs) were similar in both arms twelve months after transplantation [4].

The main outcome of DEVELOP-UK was survival at 12 months post-transplant. This was 0.67 (95\% Confidence Interval (CI) 0.4-0.83) in the EVLP arm and 0.80 (95\% CI 0.74-0.85) in the standard arm. Given the modest sample sizes a formal comparison was not attempted.

The mean cost of each EVLP procedure (reconditioning of donor lungs only) was approximately $£ 14,500$ per patient. However, EVLP patients experienced increased length of stay in the intensive care unit and needed more lung support post-transplant resulting in increased post-operative costs of $£ 22,000$ compared to standard transplant. Overall the cost of an EVLP LTx was on average around $£ 35,000$ greater than a standard LTx (using a 1:1 conversion rate).

More detail on DEVELOP-UK results can be found in the full study report [4].

\section{Aims}

The aim of this economic evaluation was to evaluate the cost-utility of EVLP transplants within the current UK National Health Service (NHS) LTx service, and to assess whether including EVLP can ease waiting lists. A model of the adult LTx service providing both standard and EVLP transplants was compared with a service including only standard transplants. The decision-analytic model was populated with DEVELOP-UK, published and clinical routine data.

\section{Methods}

\section{Analysis overview}

The target population was adults on the UK LTx waiting list, while the perspective was the UK NHS. Following National Institute for Health and Care Excellence (NICE) guidelines, the time horizon used was lifetime to capture all costs and outcomes over a patient's lifetime, with a $3.5 \%$ 
Table 1 Recipient baseline characteristics

\begin{tabular}{|c|c|c|c|c|}
\hline Recipient Characteristic & & $\begin{array}{l}\text { EVLP } \\
N=18\end{array}$ & $\begin{array}{l}\text { STANDARD } \\
N=184\end{array}$ & $\begin{array}{l}\text { Total } \\
N=202\end{array}$ \\
\hline \multirow[t]{2}{*}{ Gender } & Male $\mathrm{n}(\%)$ & $13(72.2)$ & $106(57.6)$ & $119(58.9)$ \\
\hline & Female n (\%) & $5(27.8)$ & $78(42.4)$ & $83(41.1)$ \\
\hline \multirow[t]{5}{*}{ Age (Years) } & $\mathrm{n}$ & 18 & 183 & 201 \\
\hline & Missing & 0 & 1 & 1 \\
\hline & Median & 56 & 51 & 52 \\
\hline & IQR & $46-59$ & $38-58$ & $38-58$ \\
\hline & Range & $20-64$ & $18-70$ & $18-70$ \\
\hline \multirow[t]{9}{*}{ Diagnosis } & COPD n (\%) & $5(27.8)$ & $40(21.7)$ & $45(22.3)$ \\
\hline & Cystic Fibrosis n (\%) & $4(22.2)$ & $47(25.5)$ & $51(25.2)$ \\
\hline & Interstitial Lung Disease n (\%) & $7(38.9)$ & $47(25.5)$ & $54(26.7)$ \\
\hline & Emphysema n (\%) & $0(0)$ & $26(14.1)$ & $26(12.9)$ \\
\hline & Non-CF Bronchiectasis n (\%) & $1(5.6)$ & $8(4.3)$ & $9(4.5)$ \\
\hline & Obliterative Bronchiolitis n (\%) & $0(0)$ & $2(1.1)$ & $2(1.0)$ \\
\hline & Pulmonary Hypertension n (\%) & $1(5.6)$ & $3(1.6)$ & $4(2.0)$ \\
\hline & Other $\mathrm{n}(\%)$ & $0(0)$ & $9(4.9)$ & $9(4.5)$ \\
\hline & Missing n (\%) & $0(0)$ & $2(1.1)$ & $2(1.0)$ \\
\hline \multirow[t]{3}{*}{ Diabetes } & Yes n (\%) & $4(22.2)$ & $33(18.1)$ & $37(18.3)$ \\
\hline & No n (\%) & $13(72.2)$ & $142(78.0)$ & $155(76.7)$ \\
\hline & Missing n (\%) & $1(5.6)$ & $9(3.9)$ & $10(5.0)$ \\
\hline \multirow[t]{5}{*}{ BMl } & $\mathrm{n}$ & 17 & 182 & 199 \\
\hline & Missing & 1 & 2 & 3 \\
\hline & Median & 21.6 & 23.8 & 23.7 \\
\hline & $\mathrm{IQR}$ & $18.4-26.3$ & $20.5-26.5$ & $20.4-26.5$ \\
\hline & Range & $17.6-32.5$ & $15.4-34.2$ & $15.4-34.2$ \\
\hline \multirow[t]{5}{*}{ FEV1 (L) } & $\mathrm{n}$ & 15 & 176 & 191 \\
\hline & Missing & 3 & 8 & 11 \\
\hline & Median & 1.2 & 0.9 & 0.9 \\
\hline & IQR & $0.7-1.9$ & $0.6-1.4$ & $0.6-1.5$ \\
\hline & Range & $0.5-2.5$ & $0.3-3.6$ & $0.3-3.6$ \\
\hline \multirow[t]{5}{*}{ FEV1\% } & $\mathrm{n}$ & 15 & 171 & 186 \\
\hline & Missing & 3 & 13 & 16 \\
\hline & Median & 29 & 26 & 27 \\
\hline & IQR & $22-50$ & $20-45$ & $20-45$ \\
\hline & Range & $15-67$ & $11-105$ & $11-105$ \\
\hline \multirow[t]{3}{*}{ Type of Transplant } & Single $\mathrm{n}(\%)$ & $2(11.1)^{*}$ & $24(13.0)^{* *}$ & $26(13)$ \\
\hline & Bilateral n (\%) & 16 (88.9) & $152(82.6)$ & $168(83)$ \\
\hline & Missing n (\%) & $\begin{array}{l}0(0) \\
* 1 \text { left, } 1 \text { right }\end{array}$ & $\begin{array}{l}8(4.4) \\
* * 9 \text { left, } 13 \text { right, } 2 \text { NK }\end{array}$ & $8(4)$ \\
\hline \multirow[t]{3}{*}{ Cardiopulmonary Bypass Use } & No n (\%) & $2(11.1)$ & $46(25.0)$ & $48(24)$ \\
\hline & Yes n (\%) & $16(88.9)$ & $116(63.0)$ & $132(65)$ \\
\hline & Not known n (\%) & $0(0)$ & $22(12.0)$ & $22(11)$ \\
\hline Source[4] & & & & \\
\hline
\end{tabular}

BMI body mass index, CF cystic fibrosis, COPD chronic obstructive pulmonary disease, EVLP Ex-vivo lung perfusion, FEV forced expiratory volume, IQR inter quartile range, NK not known 
discount rate for both costs and health benefits [8]. Cost-effectiveness was measured against the current NICE threshold of $£ 20,000$ to $£ 30,000$ per QALY [9].

Interventions were a UK adult LTx service combining both EVLP and standard LTxs ('EVLP service') compared to a standard LTx only service ('Standard service'). These interventions were chosen to illustrate the effect of introducing EVLP into the existing UK LTx service as a means of increasing the donor lung pool.

\section{Model structure}

A Markov model (Fig. 1) was developed using Microsoft ${ }^{\circ}$ Excel $^{\circ} 2010$ (Microsoft, Washington, USA) to extrapolate DEVELOP-UK results to a lifetime horizon. The model represents the flow through the UK adult LTx service; beginning in the 'Waiting list' state, the patient may remain or progress to one of the following states; 'Removed from the waiting list,' 'Death'; 'Receiving a standard LTx'; or 'Receiving an EVLP LTx'. Post-transplant, the patient progresses either to death or to the relevant post one-year transplant state. Cycle length was 1 year reflecting the clinically important first year following survival [10]. Costs and outcomes were assigned to each model state.

\section{Model transitions}

Transitions from the waiting list were taken from figures published by NHS Blood and Transplant (NHSBT) [11]. A cohort of 251 patients who registered for an LTx between 1 April 2011 and 31 March 2012, were followed for 3 years, covering the same time period of DEVELOPUK trial. The numbers of patients who left the waiting list each year were used to calculate transition rates.

Survival figures derived from DEVELOP-UK were not deemed robust enough for use as a model parameter due to the small number of participants in the EVLP arm and the short period of follow-up (12 months). Therefore, survival post-transplant was determined using NHSBT survival data reported for a cohort of 348 patients who received their LTx between 1 April 2004 and 31 March 2006 [12] There is no evidence in the literature, nor from DEVELOPUK, of any difference in survival post-transplant between standard and EVLP transplants [6], so the same survival was assumed for both types of transplant. DEVELOP-UK data showed a non-significant trend towards higher mortality for EVLP, however, it is important to note that due to the small sample sizes in DEVELOP-UK the data are not sufficiently comprehensive to permit a robust comparison.

One-year survival was used for 'Year 1' following both standard and EVLP transplants. For post 'Year 1' states an estimated mean post-transplant survival, which was determined using area-under-the-curve methods precluding the need for tunnel states, was applied to each transplant recipient. This was calculated using survival data at 3, 5 and 10 years post-transplant and assuming 25 years to be maximum life expectancy post-transplant (data from the International Society for Heart and Lung Transplantation (ISHLT) report that for adults receiving an LTx between January 1990 and June 2012 survival of 19 years post-transplant is $12 \%$ [13]).

\section{Model assumptions}

- The 'Removed from waiting list' state is an absorbing state, where a patient does not accrue costs or utilities (the probability attached to transitioning into this state is independent of transplant type). Patients transition to this state when they are too ill to receive a transplant, prognosis is extremely poor

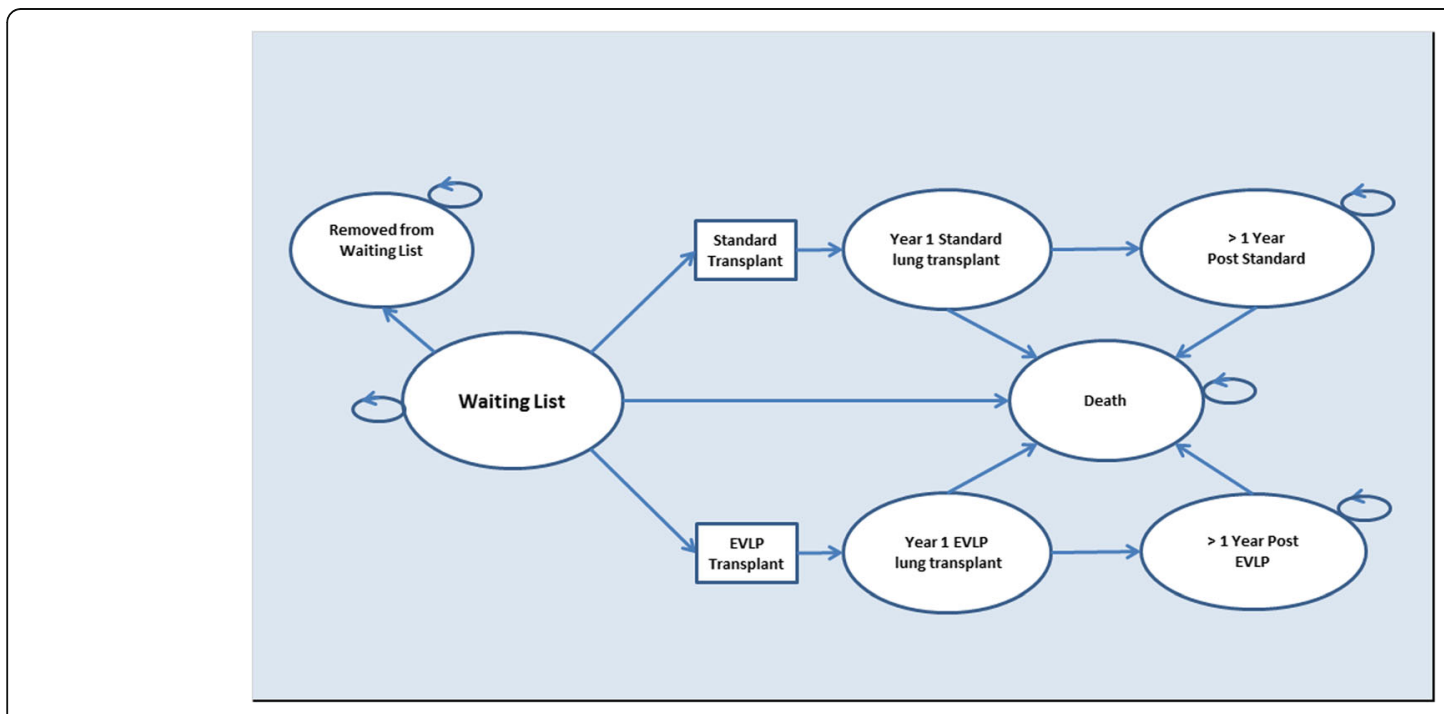

Fig. 1 Model structure 
for these patients, with survival typically less than a month, Exploratory analysis was carried out to estimate the effects of this assumption, by including costs and QALYs for patients in this state and varying the survival between 1, 3 and 6 months.

- NHSBT waiting list transitions were only available for three years post-registration. As only $5 \%$ of the cohort remained on the waiting list beyond three years, it was assumed that transitions remain constant from year three onwards.

- It was assumed that utilities at 12 months posttransplant, derived from DEVELOP-UK data, were the same for 2 years post-transplant and onwards. This assumption is backed up by previous research where utilities post double-lung transplant were similar for 7-18 months (0.83), 19-36 months (0.81) and $>36$ months (0.82) [14].

\section{Outcomes}

The principle outcome measure used was QALYs, a measure combining quality and length of life, calculated using the patients' responses to the 36-item Short Form Health Survey (SF-36) [15]. DEVELOP-UK participants completed SF-36 questionnaires whilst on the waiting list and at 3 and 12 months post-transplant. SF-36 responses were converted into SF-6D scores using the SF-6D algorithm; Values of 0 represent death, and 1 represents perfect health. Utility scores post-transplant were combined with length of survival to calculate the estimated QALYs for each patient [16]. Data were combined for the EVLP and standard transplants giving healthstate specific utilities, not varying by type of transplant.

\section{Costs}

Costs were calculated based on resource use during DEVELOP-UK [4]. Case report forms were used along with expert opinion to identify resource use within eight stages of lung transplantation; donor hospital, lung retrieval, transplant preparation, EVLP procedure, transplant surgery, post-operative care, outpatient care, and concomitant medications. Unit costs were obtained from the British National Formulary(BNF) [17], Personal Social Services Research Unit(PSSRU) [18], NHS reference costs [19], Information Services Division Scotland(ISD) [20], direct company quotes, expert opinion, hospital costing tools and medical suppliers websites. The price year used was 2016/2017 (and the currency was pounds sterling (GBP, $€$ ).

Total mean cost per participant was calculated by summing the products from unit costs multiplied by the quantities of resources used, then dividing by the number of participants per arm.

To calculate the cost for the year of transplant all costs listed above were included. For the years following, transplant outpatient and medication costs were summed and decreased annually in line with costs published by Anyanwu and colleagues [14].

During DEVELOP-UK, 53 EVLP assessments were completed resulting in 18 EVLP transplants, a conversion rate of 53:18. To reflect this in the micro-costing analysis, EVLP transplant costs were calculated by applying a 53:18 ratio to costs of the first four stages outlined above as these stages are different between the two LTx procedures. However, this ratio was not available for the standard arm and therefore, this was considered to be equal to $1: 1$.

Waiting list costs were not available using DEVELOPUK data and consequently they were obtained from a published economic evaluation of adult lung transplantation in the UK [14]. Costs for double lung transplantation waiting list were used as $83 \%$ of transplants in DEVELOP-UK were double-lung, and inflated to 2016/ 2017 price year using the Hospital and Community Health Services Index [21, 22].

Details of the costs used in the model can be found in the DEVELOP-UK report [4].

\section{Assessment of cost-effectiveness}

An incremental cost-effectiveness ratio (ICER) was calculated by dividing the difference in total mean costs by the difference in their mean outcomes between the two arms.

\section{Uncertainty}

Lack of robustness in DEVELOP-UK data as well as model assumptions and parameters created uncertainty. Because of this uncertainty, the use of point estimates to populate the model would be potentially misleading. For this reason, probabilistic sensitivity analysis (PSA) was used to estimate mean costs and QALYs for the analysis. Suitable distributions were assigned to each parameter and de facto standard 1000 simulations were carried out. Best practice was followed for PSA and the choice of parameters [23]. Model parameters and distributions are listed in Table 2, and an incremental cost-effectiveness plane and a cost-effectiveness acceptability curve (CEAC) are presented. In Table 2 the key difference in transition probabilities between EVLP and standard lung transplant is that for any given time period there is a $10 \%$ increase in the number of transplants performed. The impact of this in the model is that fewer patients will die whilst on the waiting list or transfer off the waiting list (into end of life care).

Scenario analysis investigated uncertainty by using plausible alternative parameters and analysing the effect on costs and utilities. Nine scenario analyses were carried out. The first used NHSBT transition rates from before the trial. These rates were from a cohort of patients added to the waiting list between 1 April 2008 and 31 
Table 2 Base case model parameters

\begin{tabular}{|c|c|c|c|c|}
\hline Parameters & Mean & Alpha/Beta & Distribution & Source \\
\hline \multicolumn{5}{|l|}{ Model transitions } \\
\hline \multicolumn{5}{|c|}{ From 'Waiting list' to 'Removed from waiting list' (Standard and EVLP service) } \\
\hline Year 1 & 0.020 & $5.02,245.98$ & Beta & NHSBT [11] \\
\hline Year 2 & 0.030 & $2.51,80.32$ & Beta & NHSBT [11] \\
\hline Year 3 onwards & 0.077 & $2.51,30.12$ & Beta & NHSBT [11] \\
\hline \multicolumn{5}{|l|}{ From 'Waiting list' to Transition to 'Death' (Standard and EVLP service) } \\
\hline Year 1 & 0.150 & $37.65,213.35$ & Beta & NHSBT [11] \\
\hline Year 2 & 0.212 & $17.57,65.26$ & Beta & NHSBT [11] \\
\hline Year 3 onwards & 0.077 & $2.51,30.12$ & Beta & NHSBT [11] \\
\hline \multicolumn{5}{|l|}{ From 'Waiting list' to 'Receiving a standard lung transplant' } \\
\hline Year 1 & 0.510 & $128,122.99$ & Beta & NHSBT [11] \\
\hline Year 2 & 0.364 & $30.1,52.71$ & Beta & NHSBT [11] \\
\hline Year 3 onwards & 0.462 & $15.1,17.57$ & Beta & NHSBT [11] \\
\hline $\begin{array}{l}\text { Increase in lung transplant activity due to EVLP procedure } \\
\text { (Applied in addition to standard LTx transition in EVLP service arm) }\end{array}$ & $10 \%$ & 18,184 & Beta & DEVELOP-UK data [4] \\
\hline \multicolumn{5}{|l|}{ Post lung transplant survival } \\
\hline One-year survival for standard and EVLP & 0.77 & $257.91,77.04$ & Beta & UK cardio audit [27] \\
\hline \multicolumn{5}{|l|}{ Area under the curve } \\
\hline 1-year survival & 0.77 & $257.91,77.04$ & Beta & UK cardio audit [27] \\
\hline 3-year survival & 0.7 & $225.19,96.51$ & Beta & UK cardio audit [27] \\
\hline 5-year survival & 0.53 & $167.15,148.23$ & Beta & UK cardio audit [27] \\
\hline 10-year survival & 0.34 & $116.90,226.93$ & Beta & UK cardio audit [27] \\
\hline \multicolumn{5}{|l|}{ Utilities } \\
\hline Waiting list & 0.563 & $2292.2,1782.4$ & Beta & DEVELOP-UK data [4] \\
\hline 1-year post standard lung transplant & 0.702 & $465.8,197.3$ & Beta & DEVELOP-UK data [4] \\
\hline 2 years onwards post standard lung transplant & 0.734 & $439.7,159.4$ & Beta & DEVELOP-UK data [4] \\
\hline 1-year post EVLP lung transplant & 0.702 & $465.8,197.3$ & Beta & DEVELOP-UK data [4] \\
\hline 2 years onwards post EVLP transplant & 0.734 & $439.7,159.4$ & Beta & DEVELOP-UK data [4] \\
\hline \multicolumn{5}{|l|}{ Costs } \\
\hline Waiting list cost per year & $£ 23,829$ & $103.1,239.3$ & Gamma & Anyanwu [14] \\
\hline Standard lung transplant & $£ 51,778$ & $304.2,175.5$ & Gamma & DEVELOP-UK data [4] \\
\hline EVLP lung transplant & $£ 137,527$ & $98.4,1441.1$ & Gamma & DEVELOP-UK data [4] \\
\hline
\end{tabular}

Post lung transplant costs - standard LTx (outpatient and concomitant medication Table 38 HTA report[4])

\begin{tabular}{|c|c|c|c|c|}
\hline Year 1 & $£ 9700$ & $93.5,107.1$ & Gamma & DEVELOP-UK data [4] \\
\hline Year 2 & $£ 3812$ & $93.4,42.1$ & Gamma & DEVELOP-UK data [4] \\
\hline Year 3 onwards & $£ 3506$ & $93.4,38.7$ & Gamma & DEVELOP-UK data [4] \\
\hline \multicolumn{5}{|c|}{ Post lung transplant costs - EVLP LTx } \\
\hline Year 1 & $£ 5919$ & $20.2,302.7$ & Gamma & DEVELOP-UK data [4] \\
\hline Year 2 & $£ 2326$ & $20.2,118.9$ & Gamma & DEVELOP-UK data [4] \\
\hline Year 3 onwards & $£ 2140$ & $20.2,109.4$ & Gamma & DEVELOP-UK data [4] \\
\hline
\end{tabular}

N.B. All parameters used are for a double lung transplantation where data was available for both single and double lung transplant *EVLP Ex-vivo lung perfusion, LTx Lung transplantation, NHSBT NHS blood and transplant 
March 2009 [24]. Using these transitions excludes any effects that the change in retrieval procedure (for example, unexpected increase in standard LTx) during DEVELOP-UK may have had on transition rates. The second scenario evaluated effects of raising transplant activity due to EVLP to $20 \%$, a conservative estimate [6]. The third and fourth scenarios altered the DEVELOPUK EVLP conversion rate (base-case: 53:18). A conversion rate of $45 \%$ was chosen in the third scenario because prior to DEVELOP-UK the conversion rate was anticipated to be $40-50 \%$, while the fourth scenario used a 1:1 rate to mirror the standard lung transplant conversion rate used. No relevant published economic evaluations of EVLP were found so there was no prior work regarding retrieval to transplant conversion rates in this area. The fifth scenario used published utilities from UK LTx patients [25]. These utilities were for a larger cohort than DEVELOP-UK; 87 waiting list patients; 255 transplant recipients, and although only standard LTx patient utilities were included, these were used for EVLP patients too. The sixth scenario excluded EVLP transplants completely focussing instead on an unexpected increase in standard LTx activity witnessed during DEVELOP-UK. The seventh scenario replaced UK Cardiothoracic Transplant Audit figures for 12-month survival post-transplant with 12-month survival from DEVELOP-UK. The eighth scenario used the same post-transplant inpatient care costs in both arms to explore excluding the increase in post-transplant inpatient costs seen in DEVELOP-UK, but not reported in other EVLP settings [26]. The last scenario increased the waiting list costs by $120 \%$; waiting list costs were taken from a UK study published in 2002, uplifted to 2016/17, waiting list costs are likely more expensive now than when the 2002 study was carried out due to the availability of high costs therapeutics for cystic fibrosis (CF) and idiopathic pulmonary fibrosis (IPF). Model parameters and distributions used in all scenario analyses are presented in Table 3.

\section{Ethics approval and consent to participate to DEVELOP-UK}

Ethics approval was received from the National Research Ethics Service (reference number 11/NE/0342) and NHS research and development (R\&D) approval was secured prior to commencement of DEVELOP-UK. Local NHS approvals were secured before recruitment commenced at each site. The Newcastle Clinical Trials Unit, in its capacity as study co-ordination centre, obtained a written copy of local approval documentation before initiating each centre and accepting participants into the study.

\section{Results}

Base-case results

Base-case cost-effectiveness results of the model-based economic evaluation are presented in Table 4. The incremental mean discounted lifetime cost of a LTx was $£ 4010$ (95\% CI $£ 1863-£ 6723$ ), higher in the 'EVLP service'. The incremental life-years gained 0.040 (95\% CI -0.011-0.101), higher in the 'EVLP service'. Incremental QALYs were 0.045 (95\% CI 0.007-0.091) higher in the 'EVLP service'. The incremental cost per life year gained was $£ 100,000$ and the incremental cost per QALY gained was $£ 90,000$ for the 'EVLP service' compared with the 'Standard service'. $1 \%$ of simulations fall below the $£ 20,000$ and $£ 30,000$ thresholds.

In the 'Standard service', the number of standard LTxs carried out from a cohort of 1000 was 721 . In the 'EVLP service' the number of standard LTxs and EVLP LTxs was 675 and 67 respectively, (742 in total). The number of standard LTxs decreased in the 'EVLP service' compared with the 'Standard service' as a result of the model calculating transitions from the waiting list, as probabilities. In other words, there are fewer patients left in the 'Waiting list' state at the end of each cycle in the 'EVLP service' due to EVLP transplants, so less patients transition to receive a standard LTx.

Incremental costs and QALYs were plotted on an incremental cost-effectiveness plane (Fig. 2). As can be seen, most of the simulations fell in the north-east quadrant where the 'EVLP service' had higher costs and more QALYs than the 'Standard service'. A small number (1.1\%) of simulations fell in the north-west quadrant where the 'EVLP service' had higher costs and lower QALYs than the 'Standard service'.

The CEAC (Fig. 3) illustrates that there is a 99.9 and 99.8\% likelihood of the 'Standard service' being more cost-effective than 'EVLP service' at a willingness-to-pay of $£ 20,000$ and $£ 30,000$, respectively. At a willingnessto-pay of $£ 90,000$, the 'EVLP service' begins to have a higher probability of being more cost-effective than the 'Standard service'.

\section{Scenario analysis results}

The scenario analysis results are presented in Table 5 below. The scenario analysis that resulted in the smallest effect on the ICER was increasing the EVLP rate to $20 \%$. When the EVLP rate increased to 20\%, costs and QALYs increased but the ICER was virtually unchanged as the increase in QALYs was negated by the proportionate increase in costs. Nevertheless, the number of transplants increased from 742 to 762 (2.6\% increase).

Changing the conversion rate from base-case (53:18 or $35 \%)$ to $45 \%$ decreased the ICER to $£ 65,000 / \mathrm{QALY}$ gained. However, changing the conversion rate for EVLP to 1:1 from the base-case of 53:18 resulted in an ICER of $£ 26,000$ /QALY which is at the upper end of what society might be willing to pay for a QALY in the UK [8]. These results are illustrated using a cost-effectiveness acceptability curve in Fig. 4 below. 
Table 3 Scenario analysis parameters

\begin{tabular}{|c|c|c|c|c|}
\hline Parameters & Mean & Alpha/Beta & Distribution & Source \\
\hline \multicolumn{5}{|l|}{ Scenario 1: Pre-trial model transitions } \\
\hline \multicolumn{5}{|c|}{ From 'Waiting list' to 'Removed from waiting list' (Standard and EVLP service) } \\
\hline Year 1 & 0.08 & 16,180 & Beta & NHSBT [24] \\
\hline Year 2 & 0.03 & 2,67 & Beta & NHSBT [24] \\
\hline Year 3 onwards & 0.11 & 3,32 & Beta & NHSBT [24] \\
\hline \multicolumn{5}{|l|}{ From 'Waiting list' to Transition to 'Death' (Standard and EVLP service) } \\
\hline Year 1 & 0.17 & 33,163 & Beta & NHSBT [24] \\
\hline Year 2 & 0.09 & 6,63 & Beta & NHSBT [24] \\
\hline Year 3 onwards & 0.17 & 6,29 & Beta & NHSBT [24] \\
\hline \multicolumn{5}{|l|}{ From 'Waiting list' to 'Receiving a standard lung transplant' } \\
\hline Year 1 & 0.4 & 78,118 & Beta & NHSBT [24] \\
\hline Year 2 & 0.38 & 26,43 & Beta & NHSBT [24] \\
\hline Year 3 onwards & 0.28 & 10,25 & Beta & NHSBT [24] \\
\hline \multicolumn{5}{|l|}{ Scenario 2: $20 \%$ increase in lung transplant activity due to EVLP procedure } \\
\hline $\begin{array}{l}\text { Increase in LTx activity due to EVLP procedure } \\
\text { (Applied in addition to standard LTX transition in 'EVLP service' arm) }\end{array}$ & 0.2 & 36,184 & Beta & DEVELOP-UK data $[4]$ \\
\hline \multicolumn{5}{|l|}{ Scenario 3: 45\% Conversion rate } \\
\hline EVLP lung transplant & $£ 119,672$ & $75.1,1644.4$ & Gamma & DEVELOP-UK data $[4]$ \\
\hline \multicolumn{5}{|l|}{ Scenario 4: 1:1 conversion rate } \\
\hline EVLP lung transplant & $£ 89,455$ & $42.4,2174.3$ & Gamma & DEVELOP-UK data [4] \\
\hline \multicolumn{5}{|l|}{ Scenario 5: Utilities from literature } \\
\hline Waiting list & 0.31 & $59.72,132.93$ & Beta & Anyanwu et al. [25] \\
\hline 1-year post standard lung transplant & 0.83 & $1099.12,257.82$ & Beta & Anyanwu et al. [25] \\
\hline 2 years onwards post standard lung transplant & 0.82 & $854.12,187.49$ & Beta & Anyanwu et al. [25] \\
\hline 1-year post EVLP lung transplant & 0.83 & $1099.12,257.82$ & Beta & Anyanwu et al. [25] \\
\hline 2 years onwards post EVLP transplant & 0.82 & $854.12,187.49$ & Beta & Anyanwu et al. [25] \\
\hline
\end{tabular}

Scenario 6: Increase in LTX activity (Excluding EVLP)

Pre-trial

From 'Waiting list' to 'Removed from waiting list'

Year 1
Year 2
Year 3 onwards
rom 'Waiting list' to Transition to 'Death'

0.08

0.17

0.09

0.17

Year 3 onwards

From 'Waiting list' to 'Receiving a standard lung transplant'

Year 1

Year 3 onwards

Within trial

From 'Waiting list' to 'Removed from waiting list'

\begin{abstract}
Year 1
\end{abstract}
Year 2
0.03

0.11

16,180

2,67

3,32

33,163

6,63

6, 29

78, 118

26,43

10, 25

0.28
$5.02,245.98$

$2.51,80.32$
Beta

Beta

Beta

Beta

Beta

Beta

Beta

Beta

Beta

NHSBT [11]

NHSBT [11]

NHSBT [11]

NHSBT [11]

NHSBT [11]

NHSBT [11]

NHSBT [11]

NHSBT [11]

NHSBT [11] 
Table 3 Scenario analysis parameters (Continued)

\begin{tabular}{|c|c|c|c|c|}
\hline Parameters & Mean & Alpha/Beta & Distribution & Source \\
\hline Year 3 onwards & 0.077 & $2.51,30.12$ & Beta & NHSBT [24] \\
\hline \multicolumn{5}{|c|}{ From 'Waiting list' to Transition to 'Death' } \\
\hline Year 1 & 0.150 & $37.65,213.35$ & Beta & NHSBT [24] \\
\hline Year 2 & 0.212 & $17.57,65.26$ & Beta & NHSBT [24] \\
\hline Year 3 onwards & 0.077 & $2.51,30.12$ & Beta & NHSBT [24] \\
\hline \multicolumn{5}{|c|}{ From 'Waiting list' to 'Receiving a standard lung transplant' } \\
\hline Year 1 & 0.510 & $128,122.99$ & Beta & NHSBT [24] \\
\hline Year 2 & 0.364 & $30.1,52.71$ & Beta & NHSBT [24] \\
\hline Year 3 onwards & 0.462 & $15.1,17.57$ & Beta & NHSBT [24] \\
\hline \multicolumn{5}{|c|}{ Scenario 7: DEVELOP-UK one-year survival post-transplant } \\
\hline Standard service & 0.80 & $161.8,40.4$ & Beta & DEVELOP-UK [4] \\
\hline EVLP service & 0.67 & $11.64,5.73$ & Beta & DEVELOP-UK [4] \\
\hline \multicolumn{5}{|c|}{ Scenario 8: Same costs of post-transplant inpatient care in both arms (EVLP service = standard service costs plus costs of EVLP procedure) } \\
\hline Standard service transplant & $£ 51,778$ & $304.2,175.5$ & Gamma & DEVELOP-UK data [4] \\
\hline EVLP service transplant & $£ 95,750$ & $344.74,269.29$ & Gamma & DEVELOP-UK data [4] \\
\hline \multicolumn{5}{|c|}{ Scenario 9: Increase in waiting list costs by $120 \%$} \\
\hline Increase waiting list cost & $£ 50,830$ & $96.04,529.26$ & Gamma & $120 \%$ increase \\
\hline
\end{tabular}

*EVLP Ex-vivo lung perfusion, LTx Lung transplantation, NHSBT NHS blood and transplant

In Scenario 8, when we used the same costs for post-transplant care (as reported in other EVLP settings), the ICER decreases to $£ 34,000$. Increasing the waiting list cost by $120 \%$ resulted in an ICER of $£ 26,000 / Q A L Y$. The scenario with the lowest ICER was Scenario 6; evaluating the unexpected increase in LTx during the trial, and this resulted in an ICER of $£ 20,000$ /QALY. The scenario with the greatest effect on the ICER was scenario 7 , resulting in an ICER of $£ 408,000 / \mathrm{QALY}$.

\section{Exploratory analysis}

As pointed out in the Results section 3.1, the number of standard LTxs will differ between the two services after the first cycle as a result of the increase in transplants due to EVLP transplants. An exploratory analysis was carried out to estimate the effect on the ICER of relaxing this conservative assumption. If adopting a service including EVLP increased the number of EVLP lungs and at least maintained the number of standard lungs transplanted then the net cost per patient compared to not being transplanted would be $£ 56,200$ and the mean gain in QALYs would be 4.09. Assuming there would be an extra 46 standard transplants (based on the above exploratory analysis), then the incremental cost of service including both standard and EVLP transplants, compared with a service comprising just standard LTxs, would be $£ 29,000$ per patient, considered cost-effective.

Table 4 Base-case cost-effectiveness results

\begin{tabular}{|c|c|c|c|}
\hline & & 'Standard Service' & 'EVLP service' \\
\hline \multirow[t]{3}{*}{ Discounted } & Mean costs & $£ 69,954$ & $£ 73,964$ \\
\hline & Mean life-years gained & 5.62 & 5.66 \\
\hline & Mean QALYs & 3.67 & 3.71 \\
\hline \multirow[t]{3}{*}{ Incremental } & Costs & & $£ 4010$ \\
\hline & Life-years gained & & 0.040 \\
\hline & QALYS & & 0.045 \\
\hline \multirow[t]{2}{*}{ ICER } & Life-years gained & & $£ 100,000$ \\
\hline & QALYS & & $£ 90,000$ \\
\hline \multirow[t]{2}{*}{ Number of } & Standard lung transplants & 721 & 675 \\
\hline & EVLP transplants & & 67 \\
\hline
\end{tabular}

*EVLP Ex-vivo lung perfusion, ICER Incremental costs-effectiveness ratio, QALYS Quality-adjusted life-years ICER incremental cost-effectiveness ratio 


\section{Incremental cost-effectiveness plane}

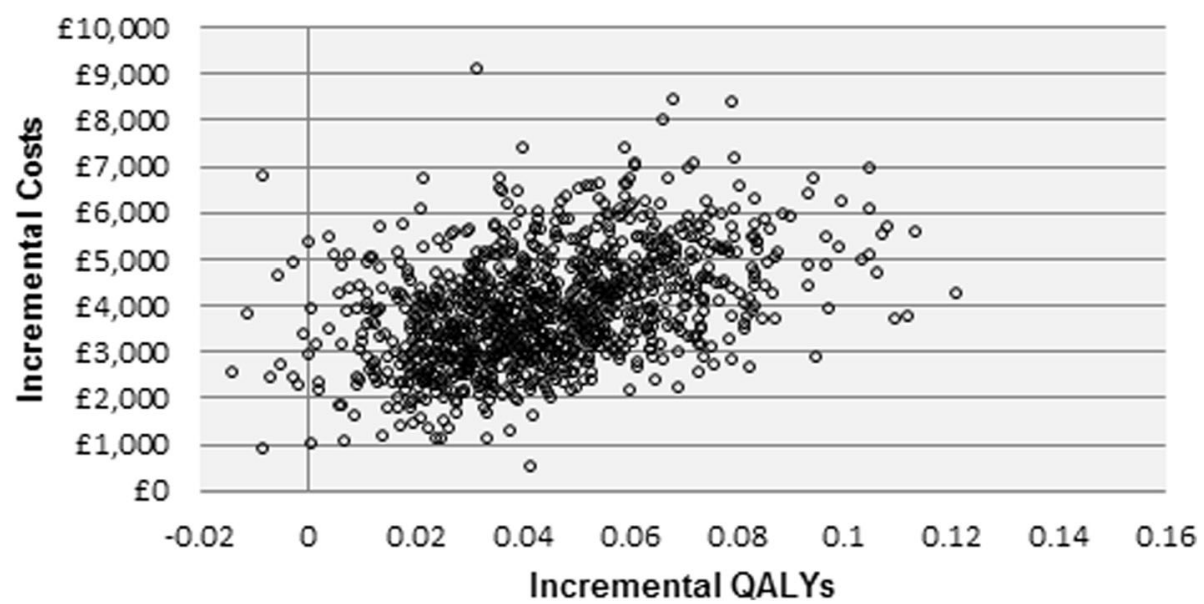

Fig. 2 Incremental cost-effectiveness plane: base-case analysis

Our second exploratory analysis relaxes the base-case assumption that costs and QALYs are not accrued to patients removed from the waiting list. The results and parameters from this exploratory analysis are presented in Table 6 below. Six more patients were removed from the waiting list in the 'Standard service' compared to 'EVLP service'. Including the costs and QALYs of these patients does not affect the results; the ICER remains at $£ 90,000 / Q A L Y$.

\section{Discussion}

\section{Main findings}

According to the findings of the study, the estimated ICER for the EVLP procedure was $190,000 /$ QALY suggesting that at the current NHS cost-effectiveness threshold, the 'EVLP service' would not be considered cost-effective [9], although it might be approved based on the NICE end-of-life criteria [8]. In the scenario analyses, the estimated ICERs were relatively stable for pre-trial transitions and EVLP rate adjustment. Changing the conversion rate (of substandard lungs to transplantable lungs) to $45 \%$ and using utilities identified from the literature increased the change in the ICER. The greatest variation on ICERs was using DEVELOPUK one-year survival post-transplant, however, it should be noted that no evidence of a difference in survival between EVLP and standard LTx has been reported in previous trials. Four scenario analyses suggested that an EVLP service might be considered cost-effective, the

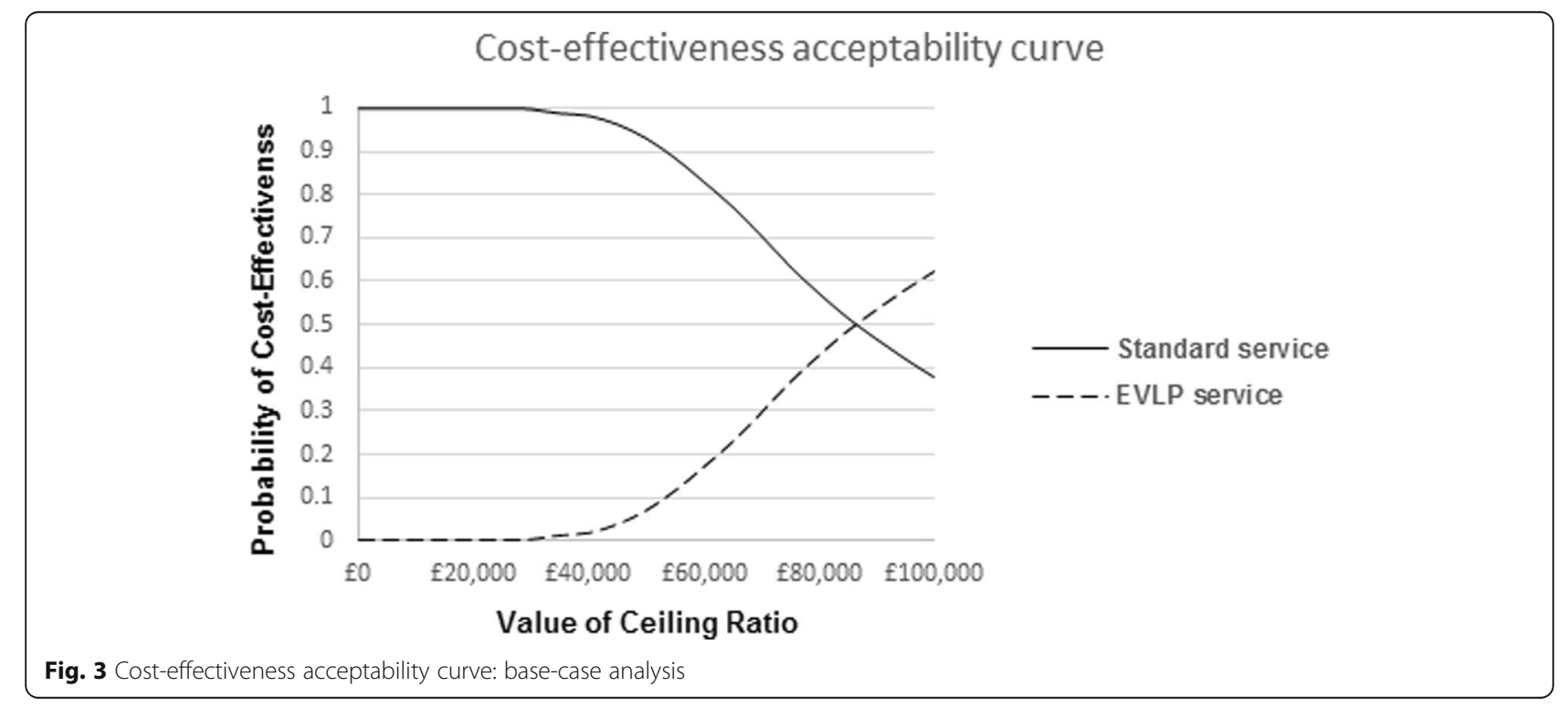


Table 5 Scenario analysis results

\begin{tabular}{|c|c|c|c|c|c|c|c|c|c|c|c|}
\hline \multirow[t]{2}{*}{ Scenario number } & \multicolumn{4}{|c|}{ Without EVLP } & \multicolumn{5}{|c|}{ With EVLP } & \multicolumn{2}{|l|}{ ICER } \\
\hline & Cost & LYG & QALYS & $\begin{array}{l}\text { Standard } \\
\text { LTx }\end{array}$ & Cost & LYG & QALYS & $\begin{array}{l}\text { Standard } \\
\text { LTx }\end{array}$ & $\begin{array}{l}\text { EVLP } \\
\text { LTX }\end{array}$ & $\begin{array}{l}\text { Cost per } \\
\text { LYG }\end{array}$ & $\begin{array}{l}\text { Cost per } \\
\text { QALY gained }\end{array}$ \\
\hline Base-case & $£ 69,954$ & 5.620 & 3.669 & 721 & $£ 73,964$ & 5.660 & 3.714 & 675 & 67 & $£ 100,000$ & $£ 90,000$ \\
\hline 1) Pre-trial transitions \& $10 \%$ & $\begin{array}{l}£ \\
65,778\end{array}$ & 5.153 & 3.304 & 620 & $£ 69,265$ & 5.199 & 3.354 & 586 & 59 & $£ 75,000$ & $£ 71,000$ \\
\hline 2) EVLP rate $20 \%$ & $£ 69,990$ & 5.613 & 3.663 & 721 & $£ 77,128$ & 5.691 & 3.747 & 635 & 127 & $£ 91,000$ & $£ 85,000$ \\
\hline 3) Conversion rate $45 \%$ & $£ 70,014$ & 5.631 & 3.679 & 721 & $£ 73,014$ & 5.673 & 3.725 & 675 & 67 & $£ 71,000$ & $£ 65,000$ \\
\hline 4) 1:1 conversion rate & $£ 70,136$ & 5.634 & 3.675 & 721 & $£ 71,300$ & 5.675 & 3.720 & 675 & 67 & $£ 28,000$ & $£ 26,000$ \\
\hline 5) Utilities from literature & $£ 69,851$ & 5.606 & 3.937 & 721 & $£ 73,941$ & 5.647 & 4.020 & 675 & 67 & $£ 98,000$ & $£ 49,000$ \\
\hline 6) Increase in standard LTx in trial & $£ 65,439$ & 5.010 & 3.200 & 620 & $£ 73,377$ & 5.500 & 3.590 & 721 & 0 & $£ 16,000$ & $£ 20,000$ \\
\hline $\begin{array}{l}\text { 7) DEVELOP-UK one-year survival post- } \\
\text { transplant }\end{array}$ & $£ 72,050$ & 5.630 & 3.670 & 721 & $£ 76,128$ & 5.620 & 3.680 & 675 & 67 & $\begin{array}{l}\text { Standard } \\
\text { dominant }\end{array}$ & $£ 408,000$ \\
\hline $\begin{array}{l}\text { 8) Same post-transplant costs plus EVLP } \\
\text { process costs in EVLP arm }\end{array}$ & $£ 69,970$ & 5.631 & 3.673 & 721 & $£ 71,569$ & 5.674 & 3.720 & 675 & 67 & $£ 37,000$ & $£ 34,000$ \\
\hline 9) Increased waiting list costs (120\%) & $£ 82,531$ & 5.628 & 3.674 & 721 & $£ 83,742$ & 5.671 & 3.721 & 675 & 67 & $£ 28,124$ & $£ 25,855$ \\
\hline
\end{tabular}

*EVLP Ex-vivo lung perfusion, ICER Incremental cost-effectiveness ratio, LYG Life-years gained, LTx Lung transplant, QALYS Quality-adjusted life-years

ICER was reduced to below $£ 30,000$ for three of these: when applying only the increase in standard LTx witnessed during the trial, assuming a 1:1 conversion rate and increasing waiting list costs by $120 \%$. Applying similar costs post-transplant forboth transplant types, as witnessed in other EVLP settings, resulted in an ICER of $£ 34,000$ suggesting that an EVLP service might be considered cost-effective.

The increase in standard transplants during the DEVELOP-UK study suggests that having access to the EVLP procedure increased recovery rates for what would previously have been deemed substandard lungs but were subsequently found to be suitable for standard transplant. The lesson is that many lungs that might initially be deemed unusable on referral may be deemed suitable on closer inspection using standard methods alone and without need for EVLP. However, this should be viewed with caution as the increase in standard LTx rates during the trial may have also resulted from other non-defined factors. EVLP assessments that did not result in a transplant were included in the study costs, however, this method was not adopted for the standard lung recovery as this information was not available. Including the costs of retrieving lungs that were not used for standard LTx could potentially alter the ICER between the two transplant procedures. The conversion rate for EVLP witnessed during the DEVELOP-UK study (53:18) was lower than the anticipated $(40-50 \%)$ and lower than the two previous largest EVLP trials, which had conversion rates of 86\% [30] from 58 EVLP assessments and $82 \%$ from 125 assessments [31]. The low conversion rate is likely a result of issues with donor lung

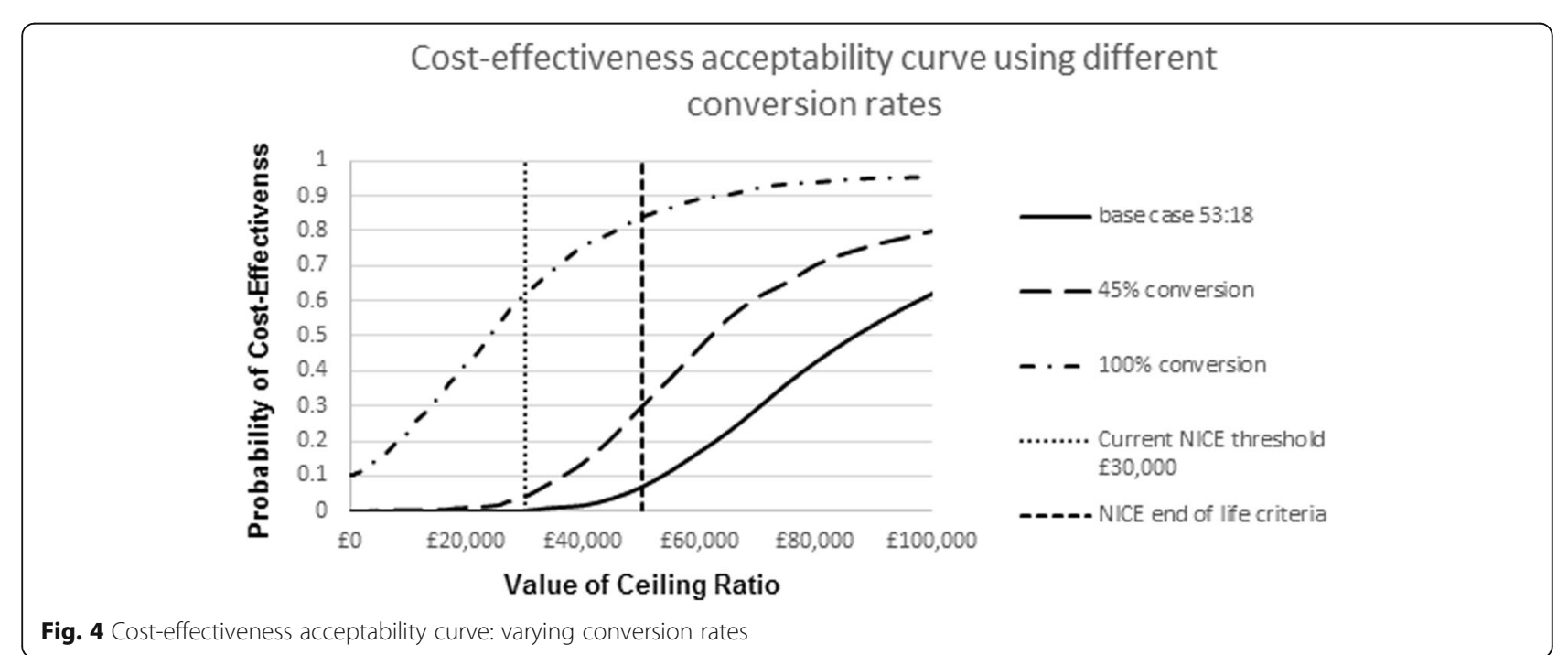


Table 6 Results of including patients who are removed from the waiting list

\begin{tabular}{|c|c|c|c|c|c|c|c|}
\hline \multicolumn{8}{|l|}{ Results of exploratory analysis } \\
\hline \multirow[b]{2}{*}{ Survival after removal from waiting list } & \multicolumn{2}{|c|}{ Without EVLP } & \multicolumn{5}{|c|}{ With EVLP } \\
\hline & Cost & QALYS & Cost & QALYS & ICER & Cost source & QALY source \\
\hline \multirow[t]{4}{*}{ One month } & $£ 69,955$ & 3.67 & $£ 73,964$ & 3.71 & $£ 90,000$ & Dzingina [28] & DEVELOP-UK [4] \\
\hline & $£ 69,955$ & 3.67 & $£ 73,964$ & 3.71 & $£ 90,000$ & Dzingina [28] & Anyanwu [14] \\
\hline & $£ 69,956$ & 3.67 & $£ 73,964$ & 3.71 & $£ 90,000$ & Georghiou [29] & DEVELOP-UK [4] \\
\hline & $£ 69,956$ & 3.67 & $£ 73,964$ & 3.71 & $£ 90,000$ & Georghiou [29] & Anyanwu [14] \\
\hline \multirow[t]{4}{*}{ Three months } & $£ 69,958$ & 3.67 & $£ 73,964$ & 3.71 & $£ 90,000$ & Dzingina [28] & DEVELOP-UK [4] \\
\hline & $£ 69,958$ & 3.67 & $£ 73,964$ & 3.71 & $£ 90,000$ & Dzingina [28] & Anyanwu [14] \\
\hline & $£ 69,959$ & 3.67 & $£ 73,964$ & 3.71 & $£ 90,000$ & Georghiou [29] & DEVELOP-UK [4] \\
\hline & $£ 69,959$ & 3.67 & $£ 73,964$ & 3.71 & $£ 90,000$ & Georghiou [29] & Anyanwu [14] \\
\hline \multirow[t]{4}{*}{ Six months } & $£ 69,961$ & 3.67 & $£ 73,964$ & 3.71 & $£ 90,000$ & Dzingina [28] & DEVELOP-UK [4] \\
\hline & $£ 69,961$ & 3.67 & $£ 73,964$ & 3.71 & $£ 90,000$ & Dzingina [28] & Anyanwu [14] \\
\hline & $£ 69,964$ & 3.67 & $£ 73,964$ & 3.71 & $£ 90,000$ & Georghiou [29] & DEVELOP-UK [4] \\
\hline & $£ 69,964$ & 3.67 & $£ 73,964$ & 3.71 & $£ 90,000$ & Georghiou [29] & Anyanwu [14] \\
\hline \multicolumn{8}{|l|}{ Parameters } \\
\hline Source & \multicolumn{2}{|c|}{ Disease area } & \multicolumn{3}{|c|}{ Parameter type } & \multicolumn{2}{|l|}{ Parameter value } \\
\hline Dzingina 2017 & \multicolumn{2}{|c|}{ Advanced chronic disease } & \multicolumn{3}{|c|}{ Palliative care cost per month } & \multicolumn{2}{|l|}{$£ 1173$} \\
\hline Georghiou 2014 & \multicolumn{2}{|c|}{ Any palliative care } & \multicolumn{3}{|c|}{ Palliative care cost per month } & \multicolumn{2}{|l|}{$£ 1644$} \\
\hline DEVELOP-UK & \multicolumn{2}{|c|}{ Lung transplant } & \multicolumn{3}{|c|}{ Quality adjusted life-years } & \multicolumn{2}{|l|}{0.563} \\
\hline Anyanwu & \multicolumn{2}{|c|}{ Lung transplant } & \multicolumn{3}{|c|}{ Quality adjusted life-years } & \multicolumn{2}{|l|}{0.31} \\
\hline
\end{tabular}

*EVLP Ex-vivo lung perfusion, ICER Incremental cost-effectiveness ratio, QALYS Quality-adjusted life-years

selection for EVLP, the inflexibility of the multi-centre protocol. Furthermore within the context of a multicentre clinical trial donor lung selection is predefined whereas data drawn from the experience of a single centre are likely to be more selective in the choice of donor to perform EVLP on.

\section{Strengths and limitations}

This is the first known economic evaluation of the EVLP technique for lung transplantation based on a multi-centre study. The strengths of this study were that all parameters used in the model were based on the UK adult LTx population. In addition, International Society for Pharmacoeconomics and Outcomes Research guidelines [32] were followed when designing the model reflecting best practice, while uncertainty in the data was evaluated using both deterministic and probabilistic sensitivity analyses. Finally, the DEVELOP-UK population is the general UK population as the study included a major proportion $(>70 \%)$ of all the lung transplantation activity over a two-year period. Therefore, the conclusions are totally relevant to UK practice.

The main limitation of the study was the low number of EVLP transplants during DEVELOP-UK meaning the outcome and use of services consequent to EVLP was imprecise and potentially unreliable. However, in the absence of other EVLP LTx data, and with DEVELOP-UK data subjected to PSA, deterministic analysis and scenario analysis, this study presents useful evidence on the potential for the EVLP technique. Evidence of higher resource use post-transplant by EVLP lung recipients in DEVELOP-UK has not been witnessed elsewhere, however this was explored in the scenario analyses by using similar costs post-transplant for both types of transplant. One model assumption was that when a patient in the 'Waiting list' state transitioned to the 'Removed from waiting list' state, no further costs or benefits were incurred. This assumption is the same as assumptions made in a Dutch economic evaluation of LTx service [33]. The cause of a removal is not known but it is reasonable to presume that most patients will be removed due to declining health. This, however, would result in higher costs and lower utilities until death. As a result, the costs are potentially underestimated and utilities overestimated in both arms; the net impact on cost-effectiveness is not possible to be predicted without information to model the costs and utilities of patients who are removed from the waiting list, however, this was mitigated by conducting the exploratory analysis which found including costs and utilities in the removed from waiting list state did not alter the ICER. 
The use of published utility rates resulted in the third largest impact on the ICER of the sensitivity analyses reported. However, caution should be exercised as the published utilities came from a 1998 cohort, since then care for patients, as well as the criteria for registering on the LTx waiting list may have changed. Waiting list costs used in the base-case analysis were taken from the same cohort and are unlikely to reflect the increased use of high cost therapies for CF and IPF available when DEVELOP-UK was conducted. The authors were unable to locate more recent UK waiting list costs for use in the model. Around 50\% of the DEVELOP-UK cohort had either CF or IPF, however, so waiting list costs during DEVELOP-UK were likely higher, a scenario analysis was conducted to explore the effect on the ICER of increased waiting list costs.

It should be noted that this evaluation is based on the UK LTx service and associated costs, therefore, whilst the model could be applied in other jurisdictions, the analysis may have limited applicability to health systems with a markedly different cost structure to the UK. The underpinning resource use data (available from the authors) may be more transferable.

\section{Comparison to other clinical evidence and future research} Despite a literature search, the authors are unaware of any other cost-effectiveness studies of EVLP LTx compared to standard LTx. One UK-based study was identified,from 1999, comparing standard LTx to medical treatment, This study reported total costs of $£ 110,078$ [14]. This is higher than the $£ 69,954$ mean standard LTx cost in our study, most of this difference results from higher post-transplant costs in the 1999 paper. This difference is likely due to several factors; early post-transplant results are better now than 20 years ago, as is overall survival and LTx centres are, when the patients are stable, also more comfortable with less frequent (and hence less costly) follow-up compared to 20 years ago.

This study has highlighted the need for more research in this area. Of particular interest are post-operative care resources, utilities and survival of EVLP recipients.

\section{Conclusion}

The aim of the economic evaluation of the DEVELOPUK study was to determine the cost-effectiveness of a UK adult LTx service including EVLP compared to one without, and the objective of including EVLP was to increase the pool of donor lungs. The results of this study suggest that combining EVLP with standard transplants increases the number of transplants, thereby reducing numbers on the waiting list. However, with the increased cost of transplant due to the EVLP procedure and the increased post-operative care costs the EVLP service is unlikely to currently be considered cost-effective, unless EVLP is deemed within the NICE remit for end-of-life care. Nevertheless, with an improved conversion rate, nearer to those witnessed in previous trials [30,31], with a lower complication rate post-transplant for EVLP transplants, witnessed in other EVLP settings, and with higher waiting list costs, including EVLP in the UK LTx service the picture could be very different.

\section{Abbreviations}

BMI: Body mass index; BNF: British National Formulary; CEAC: Costeffectiveness acceptability curve; EVLP: Ex-Vivo Lung Perfusion; FEV1: Forced expiratory volume in $1 \mathrm{~s}$; HTA: Health Technology Assessment;

ICER: Incremental cost-effectiveness ratio; ISD: Information Services Division Scotland; LTx: Lung transplant; NHSBT: NHS Blood and Transplant; NICE: The National institute for Health and Care ExcellenceDEVELOP-UKA Study of Donor Ex-Vivo Lung Perfusion in UK Lung Transplantation; NIHR: The National Institute for Health Research; NK: Not known; PSSRU: Personal Social Services Research Unit; QALY: Quality adjusted life-year

\section{Acknowledgements}

The authors would like to thank the following people for their valuable input during the DEVELOP-UK trial:

Anders Andreasson, Clinical Fellow; Tanveer Butt, Chief Retrieval/Transplant Fellow and Cardiothoracic Surgeon; John Dark, Transplant Surgeon; Paul Henderson, Perfusionist; Brian Leadbitter, NHS staff. We would also like to thank Professor Andrew Briggs for assistance with the model methodology.

\section{Funding}

The National Institute for Health Research (NIHR) Health Technology Assessment (HTA) Programme (reference 10/82/01) funded the DEVELOP-UK trial, while the Newcastle upon Tyne Hospital NHS Foundation Trust was a sponsor for DEVELOP-UK. The funding agreement ensured the authors' independence in designing the study, interpreting the data, writing, and publishing the report.

The views expressed in this publication are those of the authors and not necessarily those of the National Health Service (NHS), the NIHR, or the Department of Health and Social Care (DHSC).

\section{Availability of data and materials}

The datasets analysed during the current study are not publicly available due to consent for making individual patient level data available not being included in the DEVELOP-UK consent process, but they are available from the corresponding author on reasonable request.

\section{Authors' contributions}

NM built the model, carried out the decision analysis and drafted the manuscript. AC carried out the economic analysis of DEVELOP-UK trial data, estimated costs and helped draft the manuscript. LV conceived the study and helped draft the manuscript. AF was Chief Investigator on the DEVELOPUK trial, provided specialist advice and helped draft the manuscript. All authors read and approved the final manuscript.

\section{Ethics approval and consent to participate}

Ethics approval was received from the National Research Ethics Service (reference number 11/NE/0342) and NHS research and development (R\&D) approval was secured prior to commencement of the study. Local NHS approvals were secured before recruitment commenced at each site. The Newcastle Clinical Trials Unit, in its capacity as study co-ordination centre, obtained a written copy of local approval documentation before initiating each centre and accepting participants into the study. Informed consent was obtained from participants, either written or oral; if a potential participant had the capacity to consent for him/herself, but was unable to provide written consent because of visual or motor impairments, or literacy problems, oral informed consent was taken in the presence of an independent witness, who initialled, signed and dated the consent form on the participant's behalf. 


\section{Consent for publication}

Not applicable.

\section{Competing interests}

$\mathrm{LV}$ and $\mathrm{AF}$ received competitive peer reviewed funding from the NIHR HTA programme (reference 10/82/01) for the research reported in this paper. AC was funded from the aforementioned grant. NM has no conflicts of interest.

\section{Publisher's Note}

Springer Nature remains neutral with regard to jurisdictional claims in published maps and institutional affiliations.

\section{Author details \\ 'HEHTA, Institute of Health and Wellbeing, University of Glasgow, Glasgow, UK. ${ }^{2}$ Health Economics Group, Institute of Health \& Society, Newcastle University, Newcastle upon Tyne, UK. ${ }^{3}$ Population Health Sciences, Bristol Medical School, Canynge Hall, University of Bristol, Bristol, UK. ${ }^{4}$ Institute of Transplantation, Newcastle upon Tyne Hospitals NHS Foundation Trust, Newcastle upon Tyne, UK. ${ }^{5}$ Institute of Cellular Medicine, Newcastle University, Newcastle upon Tyne, UK.}

Received: 24 October 2018 Accepted: 8 May 2019

Published online: 22 May 2019

\section{References}

1. British Thoracic Society. The burden of lung disease: a statistical report from the British Thoracic Society, 2nd ed. London: British Thoracic Society, 2006.

2. National Institute for Health Research. A Study of Donor Ex-vivo Lung Perfusion in UK Lung Transplantation DEVELOP-UK - protocol 2013. Available from: http://www.nets.nihr.ac.uk/projects/hta/108201. Accessed 22 May 2015.

3. Cypel M, Yeung JC, Machuca T, Chen M, Singer LG. Normothermic ex vivo lung perfusion in clinical lung studies. N Engl J Med. 2011(364):1431-40.

4. Fisher A, Andreasson A, Chrysos A, Lally J, Mamasoula V, Exley C, et al. An observational study of donor ex vivo lung perfusion in UK lung transplantation: DEVELOP-UK. Health Technol Assess. 2016;20(85):1-276. https://doi.org/10.3310/hta20850.

5. Steen S, Ingemansson R, Eriksson L, Pierre L, Algotsson L, Wierup P, et al. First human transplantation of non acceptable donor lung after reconditioning ex vivo. Ann Thorac Surg. 2007;83(6):2191-4.

6. Andreasson ASI, Dark JH, Fisher AJ. Ex vivo lung perfusion in clinical lung transplantation-state of the art. Eur J Cardiothorac Surg. 2014;46(5):779-88.

7. NHS Blood and Transplant. Annual report on cardiothoracic transplantation 2014-15. 2014-2015. Available from: https://nhsbtdbe.blob.core.windows. net/umbraco-assets-corp/1304/organ_specific_report_cardiothoracic_2015. pdf. Accessed 21 July 2016

8. National Institute for Health and Care Excellence. Guide to the methods of technology appraisal: 2013. Available from: https://www.nice.org.uk/article/ pmg9/chapter/foreword. Accessed 29 Oct 2015.

9. National Institute for health care excellence. Guide to the methods of technology appraisal 2013 | foreword | guidance and guidelines | NICE. 2013.

10. National Heart Lung and Blood Institute. What are the risks of lung transplant? Available from: https://www.nhlbi.nih.gov/health/health-topics/ topics/lungtxp/risks. Accessed 2 Dec 2015

11. NHS Blood and Transplant. NHSBT - ODT Clinical Site - Annual Activity Report. 2016. Available from: https://www.odt.nhs.uk/statistics-and-reports/ annual-activity-report/. Accessed 8 Feb 2016.

12. NHS Blood and Transplant. Annual Activity Report 2017/18. 2019.

13. International Society for Heart and Lung Transplantation. Adult Lung Transplantation Statistics 2014. Available from: https://ishltregistries.org/ registries/slides.asp. Accessed 1 May 2015.

14. Anyanwu AC, McGuire A, Rogers CA, Murday AJ. An economic evaluation of lung transplantation. J Thorac Cardiovasc Surg. 2002;123(3):411-20.

15. Rand Health. 36-Item Short Form Survey from the RAND Medical Outcomes Study. 2015. Available from: http://www.rand.org/health/surveys_tools/mos/ mos_core_36item.html. Accessed 4 Nov 2015.

16. Morris S, Devlin N, Parkin D. Economic analysis in health care: Wiley; 2007.

17. British National Formulary Publications. BNF Publications. 2016 Available from: http://www.bnf.org/. Accessed 21 Jan 2016.
18. Personal Social Services Research Unit (PSSRU). Unit Costs of Health and Social Care 2013. 2015. Available from: http://www.pssru.ac.uk/projectpages/unit-costs/2013/. Accessed 12 Oct 2015.

19. National Health Service (NHS) Reference Costs. 2013/14. Available from: https://www.gov.uk/government/publications/nhs-reference-costs-2013-to2014. Accessed 12 Oct 2015

20. Information Services Division (ISD). Scotland Theatre Services. Available from: http://www.isdscotland.org/Health-Topics/Finance/Costs/DetailedTables/Theatres.asp. Accessed 3 Nov 2015.

21. Hospital and Community Health Services. Index 2007/08. Available from: http://www.pssru.ac.uk/pdf/uc/uc2008/uc2008_inflationindices.pdf. Accessed 22 Apr 2015.

22. Hospital and Community Health Services. Index 2013/14. Available from: www.pssru.ac.uk/project-pages/unit-costs/2014/index.php?file...of... Accessed 22 Apr 2015.

23. Briggs A, Claxton K, Sculpher M. Decision modelling for health economic evaluation. 2011th ed. New York: Oxford University Press; 2006.

24. NHS Blood and Transplant. Organ Donation and Transplantation Activity Report 2011-12. Available from: https://nhsbtmediaservices.blob.core windows.net/organ-donation-assets/pdfs/activity_report_2011_12.pdf. Accessed 1 May 2015.

25. Anyanwu AC, McGuire A, Rogers CA, Murday AJ. Assessment of quality of life in lung transplantation using a simple generic tool. Thorax. 2001;56(3):218-22.

26. Hopkins PM, Chambers D, Smith I, Naidoo R, Wall D, Yerkovich S, et al. Cost Effectiveness of Ex Vivo Lung Perfusion Warrants Analysis of Long Term Recipient Outcome and Donor Organ Utilization Rate. J Heart Lung Transplant. 2015;34(4):S174-S.

27. The Royal College of Surgeons of England. UK Cardiothoracic transplant audit report 2012. Available from: http://www.rcseng.ac.uk/surgeons/ research/surgical-research/docs/uk-cardiothoracic-transplant-audit-report2012. Accessed 1 June 2015

28. Dzingina MD, Reilly CC, Bausewein C, Jolley CJ, Moxham J, McCrone P, et al. Variations in the cost of formal and informal health care for patients with advanced chronic disease and refractory breathlessness: a cross-sectional secondary analysis. Palliat Med. 2017:31(4):369-77.

29. Georghiou T, Bardsley M. Exploring the cost of care at the end of life. 2014; Available from: https://www.nuffieldtrust.org.uk/research/exploring-the-costof-care-at-the-end-of-life

30. Cypel M, Yeung JC, Machuca T, Chen M, Singer LG, Yasufuku K, et al. Experience with the first 50 ex vivo lung perfusions in clinical transplantation. J Thorac Cardiovasc Surg. 2012;144(5):1200-7.

31. Cypel M, Aigner C, Sage E, Machuca T, Slama A, Stern M, et al. Three Center Experience with Clinical Normothermic Ex Vivo Lung Perfusion. J Heart Lung Transplant. 2013;32(4):S16-S.

32. Roberts M, Russell LB, Paltiel AD, Chambers M, McEwan P, Krahn M, et al. Conceptualizing a model: a report of the ISPOR-SMDM modeling good research practices task Force-2. Med Decis Mak. 2012;32(5):678-89.

33. van Enckevort PJ, TenVergert EM, Bonsel GJ, Geertsma A, van der Bij W, de Boer WJ, et al. Technology assessment of the Dutch lung transplantation program. Int J Technol Assess Health Care. 1998;14(2):344-56.

Ready to submit your research? Choose BMC and benefit from:

- fast, convenient online submission

- thorough peer review by experienced researchers in your field

- rapid publication on acceptance

- support for research data, including large and complex data types

- gold Open Access which fosters wider collaboration and increased citations

- maximum visibility for your research: over $100 \mathrm{M}$ website views per year

At $\mathrm{BMC}$, research is always in progress.

Learn more biomedcentral.com/submissions 